\title{
El CUlto DEL DETAlle EN LOS CUENTOS DE Edgar Allan PoE
}

\author{
Ezequiel Vottero \\ Universidad Nacional de Rosario \\ votteroezequiel@hotmail.com
}

Resumen: El escritor norteamericano Edgar Allan Poe llevó a cabo (a lo largo de su producción cuentística) un verdadero culto del detalle. El presente trabajo se propone la interrogación acerca del rol del detalle compositivo en la obra narrativa de Poe, y de sus vinculaciones con su propia teoría del cuento, partiendo de algunos ejemplos puntuales $y$, al mismo tiempo, privilegiados. Por último, se ocupa de analizar cómo el detalle compositivo, si bien en cierto sentido reafirma la teoría narrativa de Poe, salva también a dicha teoría de los peligros que supone una construcción tan marcadamente racional y mecanicista.

Palabras clave: Edgar Allan Poe, Cuentos, Detalle compositivo, Teoría narrativa.

\begin{abstract}
In his short stories, the American writer Edgar Allan Poe showed a real cult of detail. In this article we shall pose the question about the role of compositive detail in Poe's narrative work, and its relationships with his own theory of short story. We will first consider some examples which are detailed and privileged at the same time. Finally, we shall analyze how the compositive detail, although it reaffirms Poe's narrative theory in a certain way, it also saves this theory from the dangers that implies such a remarkably rational and mechanistic construction.
\end{abstract}

Keywords: Edgar Allan Poe, Short stories, Compositive detail, Narrative theory. 
Hacia fines del siglo XIX, el escritor escocés Robert Louis Stevenson (cuya obra recibiera, como es sabido, una influencia tan profunda por parte de Poe) señalaba, a propósito de "El tonel de amontillado" ["The Cask of Amontillado"], que todo el espíritu del cuento "depende del disfraz carnavalesco de Fortunato, el gorro de cascabeles y el traje de bufón. Una vez que Poe acertó en vestir a su víctima grotescamente, halló la clave del cuento". Stevenson ponía de este modo el acento en un detalle del relato y -no conforme con esto- lo consideraba incluso la clave del mismo. La afirmación del narrador victoriano arroja luz sobre un hecho singular: en efecto, Poe llevó a cabo (a lo largo de su producción cuentística) un verdadero culto del detalle. El presente trabajo se propone, precisamente, la interrogación acerca del rol del detalle compositivo en la obra narrativa de Poe, y de sus vinculaciones con su propia teoría del cuento, partiendo de algunos ejemplos puntuales $y$, al mismo tiempo, privilegiados.

Es en su célebre ensayo sobre Nathaniel Hawthorne, publicado en mayo de 1842, donde Poe enuncia los elementos centrales que componen su teoría del cuento:

Un hábil artista literario ha construido un cuento. Si es inteligente no habrá elaborado sus pensamientos para acomodar los incidentes, sino que, una vez concebido el efecto único o singular, inventará tales incidentes, siendo entonces cuando los combinará de la mejor forma posible para lograr el efecto pretendido. Si su primera frase no tiende a la consecución de dicho efecto, entonces ha fracasado en su primer paso. En toda composición no debería haber una palabra escrita que no tendiera directa o 
indirectamente al designio establecido; y con tales medios, con tal cuidado y habilidad, se obtiene al fin una pintura que deja en la mente del que la contempla un sentimiento de plena satisfacción. La idea del cuento ha sido presentada sin tacha porque no denota ninguna fisura, y esto es un fin inalcanzable por la novela. La brevedad indebida es precisamente tan recusable aquí como en la novela; sin embargo, todavía es más recusable la indebida longitud. (Poe, 1975, p. 570)

Todos estos elementos se centran en lo que Poe llama unidad de efecto, y "es probable", como sostiene Rolando Costa Picazo, que al desarrollar este concepto el cuentista norteamericano "tuviera en cuenta lo que August Wilhelm Schlegel denominaba Einhett des Interesse (unidad de interés) y Gesamunt Eindruck (totalidad de impresión)" (Costa Picazo, 2010, vol. I, pp. XV-XVI). En el párrafo citado Poe no hace referencia directa al lugar que ocupa el detalle de composición en su teoría del cuento (prefiere hablar, en términos más generales, de los "incidentes" del argumento), aunque implícitamente se encontraría incluido en aquella frase que señala que "en toda composición no debería haber una palabra escrita que no tendiera directa o indirectamente al designio establecido" (Poe, 1975, p. 570).

Sin embargo, cuando Poe, en su reseña de La tienda de antigüedades de Charles Dickens, decide mencionar los "puntos" más destacados de la obra, éstos son -en abrumadora mayoría- detalles (ya sean detalles descriptivos, narrativos, o de composición de los personajes). Y en esta enumeración de 
detalles, nos encontramos de pronto ante un pasaje muy sugestivo. Dice Poe: "la descripción de la casa, de la vieja iglesia y de su cementerio, todo en estricta consonancia con la única impresión que se pretende" (Poe, 1975, p. 587). Aquí podemos ver enunciado, de un modo directo, lo que estaba implícito en el ensayo sobre los cuentos de Hawthorne: el detalle compositivo - en el caso citado, de índole descriptivano debe ser ocioso, o meramente pintoresco, sino operar activamente en función de la unidad de efecto ("en estricta consonancia con la única impresión que se pretende"). Hasta tal punto el detalle adquiere para el cuentista norteamericano un lugar de suprema relevancia que, al reseñar otra novela de Dickens -Barnaby Rudge- confiesa: "Anteriormente hemos expuesto la razón de no demorarnos de modo especial en los altos méritos como en los triviales defectos de Barnaby Rudge" (Poe, 1975, p. 592), es decir, en este último caso, en detalles de la composición de la obra que le resultan censurables justamente por su inadecuación al efecto buscado.

Un ejemplo clásico de admirable adecuación de un detalle compositivo a la unidad de efecto en la obra de Poe está dado por la grieta que divide en dos a la casa de Usher. La descripción de esta grieta se enmarca en una descripción general de la mansión que ciertamente acentúa las equivalencias entre morada y moradores, pero es específicamente el detalle de la grieta el que -mencionado al comienzo del relato- jugará un papel decisivo en su desenlace. "Quizá la mirada escudriñadora de un observador", leemos en las primeras páginas, "podría haber descubierto una fisura, apenas perceptible, que se extendía por el frente desde el techo 
del edificio, se abría camino en zigzag por la pared, hasta perderse en las tenebrosas aguas del lago". ${ }^{1}$ Resulta evidente que la fisura actúa, en la narración, en dos planos diferentes y al mismo tiempo interrelacionados: por un lado, en un plano que podríamos llamar simbólico, es decir, la fisura como una imagen de la separación dolorosa -que anhela el retorno a la unidad- de Usher y de su hermana; por el otro, en un plano argumental, ya que esta mención casi distraída que el narrador hace de la grieta al comenzar el cuento se actualizará de modo terrible en el cierre:

El brillo era el de la declinante luna llena, rojo sangre, que ahora brillaba intensamente a través de la otrora apenas discernible fisura que, como he dicho, cruzaba en zigzag el edificio, desde el techo hasta la base. Ante mis ojos la fisura se fue ensanchando rápidamente, hubo luego un torbellino, cuyo feroz soplo llegó hasta donde yo estaba, el orbe entero del satélite estalló ante mis ojos, el cerebro me empezó a dar vueltas al ver las enormes paredes desmoronarse en pedazos, se oyó un largo y tumultuoso sonido ululante, como la voz de un millar de aguas, y el profundo y negro lago a mis pies se cerró tétrico y silencioso, sobre los fragmentos de la casa de Usher. (Poe, 2010, vol. I, p. 382)

Así, puede apreciarse la completa adecuación del detalle de la grieta a la unidad de efecto pretendida, debido a que -como

1 Tomando en consideración que este trabajo no se encuentra destinado a una publicación especializada en literatura angloamericana, se ha optado por incluir sólo las citas en español de los cuentos de Poe. La traducción es la de Rolando Costa Picazo (2010). 
señalábamos antes- el detalle compositivo está operando aquí tanto en el nivel argumental como en el simbólico, e incluso en lo que se refiere a la ambientación o atmósfera del relato.

Frecuentemente el detalle asume en la obra de Poe la forma de un objeto. Un ejemplo en este sentido es la linterna que acecha el "ojo de buitre" del anciano en "El corazón delator" ["The Tell-Tale Heart"]. En algunos casos, la importancia que el objeto reviste en la composición se traslada al propio título: es el caso, por ejemplo, de "El tonel de amontillado" ["The Cask of Amontillado"], "Los anteojos" ["The Spectacles"] o "La carta robada" ["The Purloined Letter"]. Si en el primero de los relatos mencionados el tonel es la carnada que le permite a Montresor cumplir su venganza sobre Fortunato, en los dos últimos los objetos respectivos -anteojos y carta- son el núcleo mismo que desencadena el equívoco o la pesquisa. "El pozo y el péndulo" ["The Pit and the Pendulum"] muestra, por otra parte, cómo dos objetos pueden coexistir -tanto en el título como en el cuento- bajo la forma de una siniestra e impuesta disyuntiva.

Otra versión sumamente interesante del detalle en Poe es lo que pudiera llamarse el detalle de biblioteca. Efectivamente, existen varios relatos en los que la enumeración de las lecturas preferidas de los personajes es notablemente reveladora de aspectos fundamentales de la trama, la ambientación, el carácter simbólico y el poder sugestivo de los mismos. En "Berenice" esta conexión es señalada explícitamente por el narrador: "Como habrá de percibirse, en esa época mis libros, si en realidad no contribuían a empeorar el trastorno, por su naturaleza imaginativa e ilógica compartían las características 
particulares del trastorno mismo" (Poe, 2010, vol. I, pp. 122123). La lista de obras comprende un tratado de Coelius Secundus Curio, De Amplitudine Beati Regni Dei, sobre el Cielo y el Infierno; La Ciudad de Dios de San Agustín, y De Carne Christi, de Tertuliano. Todas estas lecturas se vinculan, "por su naturaleza imaginativa e ilógica" según el narrador, con el carácter ilusorio que para éste adquiere la realidad ("Las realidades del mundo me parecían visiones, y tan sólo visiones, mientras que las alocadas ideas del país de los sueños se convertían, a su vez, no en la materia de mi existencia cotidiana, sino en la totalidad misma de esa existencia"; Poe, 2010, vol. I, pp. 119-120). Pero una frase proveniente de la obra de Tertuliano, que -como dice el propio personaje"ocupó por entero mi tiempo durante muchas semanas de ímproba e infructuosa investigación” (Poe, 2010, vol. I, p. 123), una frase que hace referencia a la resurrección de Cristo, adquiere un relieve inquietante en el contexto del relato, ya que la resurrección que tendrá lugar en el mismo es la de los dientes de Berenice, que serán exhumados -bajo la forma de la profanación- por el citado protagonista.

En "La caída de la casa de Usher" ["The Fall of the House of Usher'], las lecturas del personaje principal son igualmente reveladoras. Entre ellas, Belfagor, de Maquiavelo, relata la visita a la tierra que realiza un arcángel caído, con el objeto de "investigar las quejas de muchos condenados, que culpan a las mujeres por su castigo eterno" (Costa Picazo, 2010, vol. I, p. 371). Esta lectura se ilumina si pensamos en el posterior destino de Usher, quien igualmente podría señalar a una mujer 
-su propia hermana- como responsable de su muerte y de su castigo por haberla encerrado viva en la tumba. Otra de las obras presentes en la biblioteca de Usher es El viaje subterráneo de Nicholas Klimm, de Ludwig Holberg, libro que constituye "una descripción del regreso de la muerte" (Costa Picazo, 2010, vol. I, p. 372). Este regreso de la muerte tendrá su equivalente en el regreso de Madeline Usher, regreso que también consta de un origen subterráneo, ya que la bóveda en la que su cuerpo había sido depositado estaba a gran profundidad.

En lo que respecta a El viaje a la distancia aqul, del escritor romántico alemán Ludwig Tieck, podría acaso especularse que el matrimonio de su protagonista, un noble medieval, con la Reina de las Hadas se corresponde con la relación incestuosa que algunos críticos han visto entre los hermanos Usher. El influjo de otra de las lecturas de Usher ya no sería de carácter anticipatorio o simbólico, si atendemos a esta declaración explícita del narrador:

No pude evitar pensar en el estrafalario ritual de esta obra (La vigilia de los muertos según el coro de la iglesia de Mainz), y su probable influencia sobre el hipocondríaco cuando, una noche que me informó abruptamente que Lady Madeline ya no vivía, manifestó su intención de preservar su cuerpo durante una quincena (antes de su entierro final) en una de las múltiples bóvedas en las paredes principales del edificio. (Poe, 2010, vol. I, p. 373)

Por lo tanto, este detalle de biblioteca estaría directamente vinculado, si creemos en las conjeturas del narrador, con el desenlace que tendrá lugar en el relato. Resulta notable, 
además, que la lectura que acompaña el progresivo acercamiento de Madeline Usher (Mad Trist, de Sir Launcelot Canning) sea una invención de Poe. El título del libro ("Cita loca") puede verse como un paródico anticipo de la cita loca que le aguarda a Usher, al encontrarse con la hermana que ha sepultado viva.

"Morella", asimismo, presenta una nueva serie de lecturas que realizan los personajes. "El inculto panteísmo de Fichte, la palingenesia modificada de los pitagóricos y, sobre todo, las doctrinas de la Identidad, propugnadas por Schelling" (Poe, 2010, vol. I, p. 134). Todas ellas, ya sea el panteísmo de Fichte -"que postula un Dios de esencia infinita" (Costa Picazo, 2010, vol. I, p. 134) - como la filosofía de la identidad de Schelling y las ideas de reencarnación provenientes de los pitagóricos, apuntan al núcleo central del cuento: "la supervivencia de la identidad humana después de la muerte" (Costa Picazo, 2010, vol. I, p. 131).

En el caso de "Ligeia", las lecturas de los protagonistas no se describen, excepción hecha de la insistente y efectiva cita de Joseph Glanvill. Sólo se habla "del caótico mundo de la investigación metafísica" (Poe, 2010, vol. I, p. 271), por lo que podemos sospechar que algunas de las lecturas son idénticas a las mencionadas en "Morella", tomando en consideración que el tema de ambas narraciones es, esencialmente, el mismo.

El culto del detalle en Poe incluye también el literary hoax, definido por Rolando Costa Picazo como "un truco, engaño o broma literaria", y caracterizado por la parodia de "proverbios 
y expresiones idiomáticas" (2010, vol. I, p. XXXVII). En "Los asesinatos de la Rue Morgue" ["The Murders in the Rue Morgue"], "el mono (ape) que mata a las mujeres es un anagrama de E. A. P." (2010, vol. I, p. XXXVIII). El apellido de Hans Pfaall, el astronauta que viaja a la luna en un globo aerostático en el cuento homónimo de Poe, es una modificación de la palabra inglesa fall ("caída"). En "El escarabajo de oro" ["The Gold-Bug"], un criptograma juega un rol crucial en la resolución del misterio. Es interesante lo que Costa Picazo (2010, vol. I, pp. XXXIX-XL) señala en relación al literary hoax en la obra de Poe:

El literary hoax está cargado de la intención del autor, y del hecho de que él está consciente de la recepción del lector. Si, por una parte, Poe insiste sobre la "unidad de efecto" que debe producir un cuento, que debe transmitir al lector una emoción determinada, por otra parte, en muchos de sus relatos sabotea su propio ideal al impregnarlos de elementos que pueden interrumpir el trance y llamar la atención sobre sí mismos y la textura o factura del texto. Es una especie de exhibicionismo, como el del asesino que deja rastros, orgulloso de su maestría y, por qué no, de su invulnerabilidad. [...] Parece haber en Poe dos actitudes simultáneas y contradictorias: un dominio del texto y un desprecio por el texto [...]. Estos elementos verbales paródicos distraen la atención del lector del conjuro estético o trance narrativo que el mismo Poe identifica como experiencia esencial de la lectura. Impiden que el relato sea leído como una ficción autocontenida y cerrada, y establecen un subtexto. 
Pero acaso la versión más singular del detalle en Poe sea la del epígrafe. Los epígrafes de sus cuentos, en verdad, no son acotaciones ornamentales o meros comentarios sobre la materia narrativa, sino auténticos engranajes de su teoría del cuento. Son, además, inolvidables, tanto por el notable talento del autor para seleccionar frases sentenciosas y admirables como para -llegado el caso- sencillamente inventarlas. En "Metzengerstein", las palabras de Lutero dirigidas al papa Clemente VII, Pestis eram vivus, moriens tua mors ero, ${ }^{2}$ se adecúan extraordinariamente al eje argumental del relato: el enemigo de un barón húngaro reencarna en su caballo, llevándolo así a la muerte. El epígrafe de Platón que encabeza "Morella", $\alpha$ v่

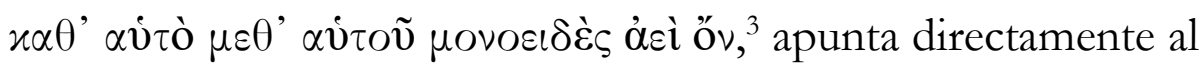
corazón del cuento: el tema de la identidad, y de su supervivencia. El de "William Wilson" (“¿Qué decís de ello? ¿Qué decís de la torva conciencia / Ese espectro de mi camino?’), parece escrito específicamente para esta narración, y esta sugerencia no se encuentra muy descaminada si tenemos en cuenta que dicho epígrafe no forma parte de la obra que consigna Poe, Pharonnida, de William Chamberlayne, sino que pertenece en parte a Poe, y en parte a fragmentos de Love's Victory, otro poema de Chamberlayne. (Este conflicto con la propia conciencia, o con el doble, es ilustrado sutilmente, además, por otro detalle del relato: en la escuela que comparten Wilson y su homónimo, "resultaba difícil", leemos (Poe, 2010, vol. I, p. 388), “decir con certeza en cuál de sus dos

2 "En vida fui tu azote; muerto seré tu muerte."

3 "Él mismo, sólo por sí mismo, eternamente UNO, y singular." 
pisos se encontraba uno", circunstancia que establece una curiosa correspondencia con la confusión o conflicto en el nivel de la identidad personal). Hay casos, como mencionábamos antes, en los que Poe presumiblemente inventa el epígrafe. El de "Berenice", que adquiere un sesgo siniestro -aunque también irónico- a la luz del posterior relato del narrador ("Mis compañeros decían que mis aflicciones se aliviarían un poco si visitaba la tumba de mi amada"), es posiblemente uno de estos epígrafes inventados, ya que Ebn Zaiat, el poeta persa o iraní al que se lo atribuye, no ha sido localizado. El epígrafe de "El escarabajo de oro" ["The GoldBug”] (“QQué hay? ¿Qué hay? ¡Este tipo baila como un loco! Lo ha picado la Tarántula"), atribuido a una obra teatral de Arthur Murphy, es, según Burton Pollin, un invento de Poe (Costa Picazo, 2010, vol. II, p. 712). La mención de la picadura (que en el relato será -aunque falsa- la del escarabajo) y el tono humorístico de la cita (muy afín a las apreciaciones supersticiosas del personaje de Júpiter) podrían abonar la conjetura de Pollin. Incluso la cita de Glanvill en "Ligeia" se halla en discusión, ya que - si bien el autor existe- "no se ha logrado localizar en sus escritos el pasaje que usa Poe como epígrafe" (Costa Picazo, 2010, vol. I, p. 264). Es llamativo, por otra parte, el papel desempeñado por el epígrafe en este texto. En efecto, el pasaje de Glanvill funciona como una suerte de objeto de la narración: si la linterna del protagonista de "El corazón delator", con su progresivo acercamiento al ojo del anciano -noche tras noche-contribuye a acentuar el clima de suspenso que caracteriza al cuento, la cita del filósofo inglés hace lo propio con el tono obsesivo que distingue a "Ligeia", 
como si la monomanía (en términos de D. H. Lawrence, y también de Roy P. Basler) que padece el narrador en su vínculo con su primera esposa, y la gradual reaparición de Ligeia sobre el cuerpo de Lady Rowena, encontraran un eco perturbador en la repetición insistente de dicha cita. Estamos ante un caso en el que el epígrafe es retomado por el texto al que encabeza: aparece en primera instancia en boca del narrador, y luego es enunciado en dos oportunidades por Ligeia (en la última de ellas, las palabras finales del pasaje de Glanvill son también las palabras finales del personaje). Es un epígrafe obsesivo, en perfecta consonancia con la atmósfera del relato.

Hasta aquí hemos expuesto las variadas adecuaciones del detalle compositivo a la unidad de efecto preconizada por Poe, aunque con algunas excepciones perturbadoras, como las señaladas por Costa Picazo a propósito del literary hoax. Sin embargo, no deberíamos concluir sin advertir que, así como el culto del detalle compositivo reafirma en cierto sentido la teoría narrativa de Poe, también salva a dicha teoría de los peligros que supone una construcción tan marcadamente racional y mecanicista. El propio autor era muy consciente de estos peligros. En "La filosofía de la composición" afirma:

Las ideas tan hábilmente dispuestas, o lo que es lo mismo, con un orden de incidentes tan evidente, siempre llevan consigo cierta dureza o desnudez que repele al ojo artístico. Se requieren dos cosas invariablemente: primero, algo de complejidad o, mejor dicho, de adaptación; y, en segundo lugar, algo de sugestividad: una corriente oculta de 
significado que, sin embargo, resulte indefinida. (Poe, 1975, p. 598)

Está hablando de la poesía, pero es sabido que Poe trasladó a su producción en prosa las mismas exigencias. Y el detalle compositivo, evidentemente, opera con frecuencia en sus cuentos contra esa dureza o desnudez que los amenaza, dotándolos de complejidad y poder sugestivo, enriqueciéndolos con diversas capas de sentido. Contribuye, además, de modo decisivo, al logro de esa gradualidad a la que el autor se refiere en más de una ocasión ("el efecto graduado del objeto", la "variación y graduación" del "clímax") (Poe, 1975, p. 598). ¿No es ésta la función que cumplen, precisamente, los minuciosos detalles concedidos a la progresiva reaparición de Ligeia en la persona de Rowena? ¿No están estos detalles trabajando de modo activo para la obtención de ese efecto graduado al que Poe aspira, evitando así la dureza que supondría una reaparición brusca, súbita, del personaje? Lo mismo cabe decir del detalle de vestuario captado por Stevenson en "El tonel de amontillado" ["The Cask of Amontillado"], con el que comenzáramos este análisis. ¿Por qué el traje de bufón de Fortunato y su gorro de cascabeles son la clave del cuento para Stevenson? Sin duda, porque en el tintineo de los cascabeles se agitan el temor y la vana esperanza del personaje, y en su traje de bufón se halla cifrada la bufonería de la condición humana. Lo que late en los cascabeles de Fortunato es esencialmente el pulso humano de la narración. De este modo, el detalle de vestuario transforma a lo que sin él sería meramente un notable relato efectista en una obra de arte. 


\section{Referencias Bibliográficas}

Fuente

Poe, E. A. (1969-1978). The Collected Works (3 vols.). Cambridge, Mass: Harvard University Press.

Estudios

Armiño, M. (Ed.). (1975). Los crímenes de la calle Morgue de Edgar Allan Poe. Barcelona: Biblioteca Clásica Sopena.

Bloom, H. (Ed.). (1985). Edgar Allan Poe: Modern Critical Views. New York: Chelsea House.

Bowra, C. M. (1949). The Romantic Imagination. Cambridge, Mass: Harvard University Press.

Carlson, E. W. (Ed.). (1966). The Recognition of Edgar Allan Poe: Selected Criticism Since 1829. Ann Arbor: University of Michigan Press.

Costa Picazo, R. (2010). "Introducción”. En Cuentos completos de Edgar Allan Poe (trad. esp. R. Costa Picazo). Buenos Aires: Colihue, vol. I, pp. VII-LXXXIV.

Hough, R. L. (Ed.). (1965). Literary Criticism of Edgar Allan Poe. Lincoln: University of Nebraska Press.

Lawrence, D. H. (1982). Estudios sobre literatura norteamericana clásica. Buenos Aires: Centro Editor de América Latina.

Parks, E. W. (1964). Edgar Allan Poe as a Literary Critic. Athens: University of Georgia Press.

Poe, E. A. (1975). "Nathaniel Hawthorne", "Barnaby Rudge” y "La filosofía de la composición". En Obras Inmortales. Madrid: EDAF. 
Poe, E. A. (2010). Cuentos completos (trad. esp. R. Costa Picazo). Buenos Aires: Colihue.

Pollin, B. R. (1985). The Brevities, Collected Writings of Edgar Allan Poe. New York: Chelsea House. 